Para enlazar con este artículo / To link to this article:

http://dx.doi.org/10.14198/fem.2017.30.02

Para citar este artículo / To cite this article:

Casado Presa, Cristina. «Y no vivieron felices para siempre: la reescritura del cuento de hadas y la problemática de la subjetividad femenina en Nueva historia de la princesa y el dragón de Carmen Resino». En Eva García-Ferrón y Cristina Ros-Berenguer (coords.), Dramaturgia femenina actual. De 1986 a 2016. Feminismo/s, 30 (diciembre 2017): 31-46, DOI: 10.14198/fem.2017.30.02

\title{
Y NO VIVIERON FELICES PARA SIEMPRE: LA REESCRITURA DEL CUENTO DE HADAS Y LA PROBLEMÁTICA DE LA SUBJETIVIDAD FEMENINA EN NUEVA HISTORIA DE LA PRINCESA Y EL DRAGÓN DE CARMEN RESINO
}

\author{
AND THEY DIDN'T LIVE HAPPILY EVER AFTER: \\ THE REWRITING OF THE FAIRY TALE AND \\ THE PROBLEMATIZATION OF FEMALE SUBJECTIVITY \\ IN NUEVA HISTORIA DE LA PRINCESA Y EL DRAGÓN \\ BY CARMEN RESINO
}

\author{
Cristina CASADO PRESA \\ Washington College, Maryland \\ ccasadopresa2@washcoll.edu \\ orcid.org/0000-0001-5767-4119
}

\section{Resumen}

Este artículo propone una lectura de Nueva historia de la princesa y el dragón (1989), de Carmen Resino, en clave de cuento de hadas feminista. Enmarcada en la nueva dramaturgia femenina que irrumpe en la escena española en la década de los 80, analizaremos cómo el drama de Resino se sirve del intertexto del cuento de hadas tradicional para parodiarlo, destruirlo y reemplazarlo. En esta pieza de Resino, este referente universal que es el cuento de hadas sirve para analizar y problematizar las complejidades y paradojas del proceso de identidad femenino, subraya el conflicto entre las expectaciones culturales y las necesidades personales, lo público y lo privado, y la conflictiva relación entre mujer y poder, que imposibilita el resolutivo final de «y vivieron felices para siempre».

Palabras clave: Carmen Resino, dramaturgia femenina, cuentos de hadas, feminismo, España. 


\begin{abstract}
This article proposes a reading of Nueva historia de la princesa y el dragón (1989), by Carmen Resino. Framed in the new drama written by women in the scene of Spain in the 80s, we will analyze how the play uses the intertext of the traditional fairy tale in order to parody, destroy and replace it. In this piece, the universal referent of the fairy tale is the vehicle to analyze and problematize the complexities and paradoxes of the feminine identity process, underlines the conflict between cultural expectations and personal needs, and the conflictive relationship between women and power, which makes the conclusive ending "and they lived happily ever after» impossible.
\end{abstract}

Keywords: Carmen Resino, female playwrights, fairy tales, feminism, Spain. 


\section{INTRODUCCIÓN}

Carmen Resino forma parte del grupo de dramaturgas a las que Patricia O'Connor denominó como el «reto de la democracia» $(1988,49)$ y que también pertenece a la generación que sufre el «desencanto» que parece dominar a la sociedad española después de la euforia inicial tras el fin de la dictadura y la instauración de la Democracia ${ }^{1}$.

La década de los 80 supone para el teatro español el auge de una serie de autores masculinos como José Luis Alonso de Santos, José Sanchis Sinisterra, Ignacio Amestoy o Fermín Cabal, quienes prefieren en su producción teatral situaciones cotidianas que permitan crear un teatro crítico, mientras buscan un público nuevo que se vea reflejado en sus obras. Su dramaturgia, al mismo tiempo que la desaparición de la censura y la vinculación de estos autores con el teatro independiente, permite una experiencia teatral más allá del texto, en tanto que han sido, o son, actores y directores ${ }^{2}$.

1. Velázquez y Memba definen esta generación como «perdida y fragmentada» (16), una generación que fue incapaz de derribar al dictador y tuvo que conformarse con su muerte, lo que les hizo cuestionar si serían capaces de desplazar a los franquistas reconvertidos sin el apoyo de una oposición fuerte. En consecuencia, después de 1977, etapa de activismo político y participación sin precedentes, llegaron esos años desencantados, entre 1979 y 1981, caracterizados por un «escepticismo, próximo, en muchos casos, a la desesperación» (16).

2. Sirva como ejemplo el hecho de que Sinisterra organizara el grupo Teatro Fronterizo, que desde 1977 representa textos que se sitúan en el límite de la teatralidad, creando una especie de nueva categoría fronteriza entre géneros que se aparta de la moda de la espectacularidad. Su obra dramática siempre está caracterizada por su posición alternativa a los lenguajes teatrales tradicionales, aunque aparezcan inscritos en las estéticas más variadas. De hecho, al propio teatro dedica textos como ¡Ay Carmela! (1987) o El lector por horas (1999). Por su parte, José Luis Alonso de Santos insiste en el tratamiento de personajes que tienen razones suficientes para estar dentro de la delincuencia, pero al presentarlos en clave de sainete colabora de manera extraordinaria a su buena recepción, como en el caso de La estanquera de Vallecas (1981) o Bajarse al moro, (1985). Por otro lado, una de las obras más conocidas de Ignacio Amestoy, Dionisio Ridruejo, una pasión española (1982), propone un verdadero drama político con ribetes de tragedia que abre las inmensas posibilidades que muestra el autor para ese género. El caso de Fermín Cabal viene marcado en gran medida por su procedencia del teatro independiente. Pese a su tonalidad realista, no desperdicia referencias simbólicas muy eficaces, como se hace

Feminismo/s 30, diciembre 2017, pp. 31-46 
Es indudable que la producción teatral femenina de la época comparte numerosos rasgos con la de sus colegas masculinos, ya que también pugna por la introducción de discursos alternativos y se aleja de las representaciones convencionales. No obstante, también lucha por el reconocimiento de la existencia de una dramaturgia femenina con un lenguaje propio. En este sentido, en un coloquio moderado por Lourdes Ortiz en 1987 que después publicaría la revista Primer Acto, Paloma Pedrero considera que «hay todo un lenguaje femenino -teatral en este caso- que debe ser proyectado», a lo que Maribel Lázaro añade que, como dramaturgas, buscan «elevar a nivel protagonista» su mundo (15). En consecuencia, estas autoras ofrecen personajes, temas y discursos que se resisten a las normas y limitaciones del orden establecido, ejerciendo una crítica más o menos explícita ante las tendencias predominantes de la cultura española en relación a la problemática femenina. Obviamente estas restricciones no son tan fuertes como durante la dictadura de Franco (19391975), pero aún es posible encontrarlas en la sociedad española de la época, donde el clima de aperturismo y cambio se conjuga con el peso de la represión y los valores tradicionales que aún siguen vigentes en la memoria colectiva.

De esta forma, estas piezas teatrales contribuyen a poner de manifiesto que estos años no son tan abiertos o tolerantes como podría parecer, por lo que esta producción dramática exhibe una mirada inconformista y crítica ante un contexto social y cultural específico. Asimismo, todas estas obras se pueden leer desde una perspectiva feminista, la cual ofrece un discurso alternativo capaz de cuestionar la representación femenina hasta el punto de poder permitirnos hablar del surgimiento de una nueva estética teatral femenina. El principal vehículo del que se sirven estas dramaturgas no es otro que unos personajes femeninos claramente transgresores que intentan desestabilizar algunas tradiciones imperantes en el contexto de la España contemporánea.

Patricia O'Connor, una de las investigadoras que, como sabemos, más ha contribuido, no solo al descubrimiento, sino también a la promoción de este grupo de autoras españolas, fue la principal responsable de su carta de presentación. El número especial de la revista Estreno, en el otoño de 1984, no deja lugar a dudas sobre su intención de mostrar al público «quiénes son las dramaturgas españolas y qué han escrito». En un número monográfico, dedicado íntegramente a la producción teatral femenina, O'Connor plantea una serie de preguntas a un grupo de figuras femeninas del entorno teatral y

patente en sus obras Tú estás loco, Briones (1978), Fuiste a ver a la abuela??? (1979) o Vade retro! (1982). 
literario en general, partiendo de la premisa de que antes de mediados del siglo $\mathrm{XX}$, apenas había dramaturgas en España:

Estrenaban alguna que otra pieza teatral Gertrudis Gómez de Avellaneda, Emilia Pardo Bazán o Concha Espina, pero no se les recuerda principalmente por su dramaturgia. Aunque en la posguerra ha salido una verdadera pléyade de escritoras brillantes en la novela, el cuento y la poesía, sigue escaseando la mujer que escribe para teatro; aun es más raro que estrene. $(1984,13)$

Los interrogantes que lanza O'Connor buscan razones que puedan explicar esta curiosa ausencia de la mujer en la dramaturgia contemporánea, y así, se plantea la aptitud de la mujer para escribir teatro, se cuestiona también la existencia de intereses y prejuicios especiales que le cierran el paso a los escenarios. Asimismo, alude a la creencia de que la mujer prefiere expresarse simple y espontáneamente a través de la confesión íntima, y discute las razones por las que el escenario teatral parece ser tan inasequible para las mujeres.

Ante estas cuestiones, lo que se desprende de las declaraciones de estas escritoras, a pesar de una cierta variedad de respuestas, es que existe una problemática común y reconocida en tanto que todas las entrevistadas coinciden en algunos aspectos: todas admiten las trabas que las mujeres sufren para representar sus obras de teatro debido a unos prejuicios que no han considerado a la mujer apta para la faceta de autora o directora de teatro; de igual manera, y significativamente, todas describen el mundo teatral y su ambiente como cerrado y masculino.

Patricia O'Connor amplió su exploración sobre la producción teatral femenina en más estudios, aparte del famoso número de Estreno, siendo el más reconocido su indispensable obra Dramaturgas españolas de hoy. Una introducción. En ella O'Connor da un paso más en su investigación, tratando de dar con las razones que han llevado a tan acusado silencio femenino en el teatro español, y centra su atención en razones sociales y culturales en las que cobra gran importancia la propia historia de España. En efecto, la especial mezcla cultural española, es, sin duda, el punto de partida para originar la arraigada opinión de que la mujer no debe invadir el dominio masculino, es decir, la esfera pública, ni con su presencia ni con sus palabras. Según recoge O'Connor, en este sentido ha tenido gran peso la costumbre islámica conocida como «purdah», que significa cortina o reclusión femenina, reforzada en la tradición clásica por Platón, combinada con parecidas actitudes greco-romanas, judías y cristianas, y perpetuada en obras como La perfecta casada de Fray Luis de León (1583). Todo ello contribuyó a forjar esa imagen de la mujer virtuosa y callada, dedicada a su hogar, cuyo consuelo era creerse «reina de la casa» (10), un dechado de virtudes en los que la modestia y la sumisión brillan con 
luz propia y, además, «haciendo sinónimos ignorancia e inocencia», lo que convierte a la mujer instruida en objeto de burla (O'Connor 1988, 15)3.

Partiendo de estas premisas, O'Connor concluye que no es de extrañar que, examinando la producción teatral femenina en España en las décadas de los 40 y 50, la encontremos escasa, y que además presente características que son, en cierto modo, bastante previsibles y limitadas a la representación de un idealizado e inexistente mundo femenino. En estos dramas destaca la exaltación de la mujer virtuosa y sumisa, la mujer como complemento a exhibir: un objeto. Como recoge O'Connor, este tipo de teatro, que ignora la subjetividad femenina, sigue vigente en décadas posteriores. Se da mucha importancia a los personajes masculinos, mientras que se repiten los estereotipos femeninos negativos, de forma que se perpetúa el canon patriarcal «al intercalar intertextos y códigos masculinos» $(1988,44)$.

Frente a esta producción marcadamente tradicional, los primeros indicios de cambio se vislumbran en las décadas de los 60 y 70, que muestran un tímido esfuerzo por equilibrar los roles femeninos y masculinos. No obstante, no es hasta mediados de la década de los 80 que es posible apreciar un cambio, al aparecer una nueva concepción teatral que denota orgullo de la identidad femenina. En palabras de O'Connor: «a new awareness and pride in women increasingly pervades the plays of the new women playwrights and the nonconformist writers of the Franco era» $(1990,311)$.

Virtudes Serrano considera que se pueden distinguir dos actitudes estéticas y personales: la de la «inversión del canon establecido y búsqueda de nuevos caminos», claramente renovadora; y la de la coexistencia con él a pesar de una disconformidad que califica de «moderada» $(1994,357)$. Estas nuevas posiciones estarán reflejadas en obras que prestan especial atención a la mujer, rechazando las visiones y límites del pasado, para dar paso a un discurso genuinamente femenino. No obstante, autoras como Raquel García Pascual matizan que «la suya no es creación únicamente con mujeres, sobre

3. Urszula Aszyk coincide con O'Connor en la escasez de dramaturgas en España, pero resalta que al contrario que en otros países, y con excepciones como Santa Teresa, las españolas no tuvieron acceso a los libros hasta bien entrado el siglo XIX, describiendo a numerosas escritoras como «autodidactas». También se hace eco de la herencia cultural española reseñada por O'Connor, y añade: «Por lo que se refiere al teatro, las espectadoras españolas del siglo XVI y XVII, es decir, de la época del Siglo de Oro y del gran desarrollo de los corrales de comedias, quedaban separadas de los espectadores hombres, lejos del espacio escénico, en la incómoda cazuela. Y sólo algunas privilegiadas podían ver el espectáculo desde las ventanas de las casas vecinas, pero también ellas estaban aisladas del espacio teatral por las rejas. Las que como actrices salían al escenario, se convertían, claro está, en mujeres públicas» (48). 
mujeres, para mujeres» (324) y argumenta que no buscan marcar distancias con otros creadores, sino con los códigos de convivencia patriarcales. Por lo tanto, aunque estas autoras rechazan la etiqueta de feministas, los efectos de la segunda ola de feminismo influyen en su toma de conciencia de los efectos del patriarcado y en la forma en la que este concibe a la mujer como un ser domesticado, pasivo y dependiente.

Como bien señala M. Jesús Salinero Cascante, tradicionalmente «la mujer está hecha para ser contemplada hasta en el último detalle de su anatomía corporal» (51), y esta tradicional representación le depara una posición de supeditación y pasividad, limitada a la función de complemento de la parte dominante, la masculina. Cuando esta representación de mujer es trasladada al terreno del teatro, nos encontramos con que tradicionalmente ha sido la mirada masculina la que ha creado estas representaciones de mujer, mientras que las propias interesadas han adoptado e interiorizado la recreación masculina que de ellas se ha hecho.

\section{DRAMATURGIA FEMENINA DE LOS 80 Y LA PROBLEMÁTICA DE LA SUBJETIVIDAD FEMENINA}

En contraposición a estas generaciones anteriores, la generación de dramaturgas de los 80 empieza a cuestionar cómo se mantiene, promueve o muestra la normativa de género vigente y ofrece alternativas de representación, donde la mujer va a cobrar el protagonismo al formular discursos transgresores; discursos que invitan a la reflexión por parte de la audiencia, a la que se le ofrecerá, por lo tanto, mirar a través de otros ojos distintos. Ya que la estructura y el mantenimiento de las relaciones de género se basan en normas culturales, una exposición de estas puede llevar a su cuestionamiento, y de ahí a su transformación y cambio. En consecuencia, esta producción dramática nace del reconocimiento de una representación indebida, lo que lleva a la protesta por el tipo de personajes representados e, inevitablemente, busca una forma de producción que rompa con las anteriores. Así, se va a «re-presentar» a las mujeres como sujeto, es decir, trasladar los problemas de la mujer, sus experiencias y sus historias al centro del escenario.

Esta generación de dramaturgas muestra diferentes tipos y grados de opresión femenina, al tiempo que los rechaza a través de estrategias de subversión ${ }^{4}$.

4. Además de Carmen Resino, existen numerosas autoras cuyas piezas comparten estas características. Por ejemplo, Maribel Lázaro recrea la caza de brujas en la Galicia del siglo XVII en Humo de Beleño (1986), Pilar Pombo recupera la Guerra Civil española en su drama En igualdad de condiciones (1996). Por otra parte, Lidia Falcón retoma la historia más reciente con Las mujeres caminaron con el fuego del siglo. Concha Romero 
En suma, esta dramaturgia anticipa una liberación de la relación jerárquica entre el hombre y la mujer y una clara intención de reescribir las tradicionales prescripciones de género.

Carmen Resino publica su primera obra en 1969 con el título de El presidente, pero su nombre comienza a sonar con fuerza en la década de los 80, cuando, tal y como señala Mariano de Paco, «en pleno auge creador de los autores realistas, iniciaban su andadura los autores del nuevo teatro; sin embargo, a causa del habitual olvido [...] no es su obra conocida como se merece» (304). Desde entonces, sus piezas han ido delineando una propuesta teatral en la que destaca el tema de la mujer en una sociedad dominada por hombres. De acuerdo con Jon Gabriele, «la obra dramática de Resino emprende a nivel específico la investigación de la identidad femenina y a nivel universal el sondeo de la situación del individuo cuya libertad de expresión personal le es impedida por tácticas autoritarias» (93). Asimismo, estudiosos como De Paco resaltan su capacidad de usar la historia como «marco de referencia o ambientación en el que crea liberalmente historias, situaciones o personajes» (304), haciendo hincapié en el interés de la autora por «la problemática relación entre los individuos y el destino. Las dificultades para lograr la propia realización; la frustración que continuamente amenaza a los seres humanos por el hecho de serlo» (304).

\section{NUEVA HISTORIA DE LA PRINCESA Y EL DRAGÓN COMO UNA APROPIACIÓN FEMINISTA DEL CUENTO DE HADAS TRADICIONAL.}

Nueva Historia de la princesa y el dragón ha sido descrita por Patricia O'Connor como «allegory of Women's anxiety about authority» $(1988,387)$, y reúne todos los rasgos de la dramaturgia de Resino descritos anteriormente. Del mismo modo, permite una lectura feminista como subversión de la vieja tradición del cuento de hadas para contar una nueva historia desde el punto de vista de la mujer.

Cuando hablamos de Nueva historia como la reescritura de un cuento de hadas, debemos entenderla como una respuesta en contra de las relaciones de poder, que son una de las premisas centrales en los cuentos tradicionales, pero también en las interpretaciones feministas más modernas. Esto se hace evidente en el hecho de que, en numerosos cuentos de hadas populares, el

publica en 1983 Un olor a ámbar, obra que tiene como protagonista el cuerpo incorrupto de Santa Teresa, mientras que su obra Las bodas de una princesa (1982) muestra a una jovencísima Isabel de Castilla en su difícil camino al trono. Romero retoma de nuevo la figura de la reina Isabel en sus últimos años de vida y el conflicto con su hija Juana en Juego de Reinas (1991). 
personaje principal femenino (la princesa, en muchas ocasiones) se encuentra en peligro, su príncipe encantador la rescata, y viven felices para siempre. En consecuencia, las mujeres son presentadas a menudo como personajes dóciles y maternales, mientras que los hombres aparecen como personajes poderosos y resueltos. Estas historias han modelado, como afirma Gilbert, lo que una cultura considera un final feliz o infeliz (129), mientras Karen Rowe añade: «traditional fairy tales fuse morality with romantic fantasy in order to portray cultural ideals for human relationships»(209). Es más, Jack Zipes, en Fairy Tales and the art of subversion describe los cuentos de hadas como elementos que sutilmente influyen en la sociedad a la hora de ver el mundo. Zipes subraya cómo estos cuentos ofrecen una representación de los roles tradicionales de género y sus comportamientos. Adicionalmente, advierte que los lectores impresionables verán estas representaciones como una manera de confirmar el destino de un personaje según su género.

Por otra parte, como declara Donald Hasse, «awareness of the fairy tale as a primary site for asserting and subverting ideologies of gender is evident throughout the genre's story» (2), e insiste en la necesidad de nuevas aproximaciones «that can situate the fairy tale's treatment of gender in relation to the diynamics of history and the shifting boundaries of society, culture and nation» (12). En este sentido, como respuesta a la tradición, es posible apreciar una serie de reescrituras o reinterpretaciones de estas historias tradicionales, tanto que ponen de relieve cómo revierten aquello que de mentalidad patriarcal y de imposición de género se puede apreciar. Estas versiones del cuento tradicional promueven un diálogo donde la prevalencia de los discursos masculinos es expuesta y criticada, y proponen alternativas a estas posiciones tradicionales de género.

Así, podemos apreciar la proliferación de cuentos de hadas en clave feminista que, o bien reescriben los tradicionales, o bien se apropian de los mismos como intertextos para transmitir un discurso de género. Esta nueva producción cultural busca dar voz a la mujer, y exponer a través de la subversión de los presupuestos tradicionales las limitaciones de los roles de género, sus estereotipos y los modelos conservadores de comportamiento.

Carmen Resino nos advierte de sus intenciones desde el mismo título de la pieza, donde la historia de la princesa y el dragón, evocadora de numerosos cuentos, es alterada con la inserción de la palabra «nueva». El drama gira alrededor de la princesa Wu-Tso, quien debe aceptar un matrimonio de Estado con el débil heredero del trono japonés, en contraposición a su deseo de ser la heredera de su padre y sentarse en el trono de China. Wu-Tso muestra un carácter desafiante desde el principio del drama, cuando se enfrenta a su padre acerca de su derecho a ser emperador antes que su hermano: «Soy mejor que 
él, física y moralmente, tú lo sabes. Y además soy la primogénita» (11). Aun sabiendo que las palabras de $\mathrm{Wu}$-Tso son ciertas, la respuesta del emperador es simple a la par que reveladora: «Pero es varón» (11). Wu-Tso tampoco encuentra apoyo en su madre, quien ante las protestas de la joven solo atina a contestar: «No tienes que maldecir tu destino. Las mujeres, hija, lo tenemos tan abocado a las desgracias que el tuyo debería parecerte un privilegio» (29). En consecuencia, Wu-Tso es enviada a Japón, desposándose por obligación con un hombre al que desprecia y ganándose desde el primer momento la enemistad de la emperatriz, quien la considera un peligro para la dinastía y la sucesión.

Sin embargo, Wu-Tso, a través de una serie de maniobras tan maquiavélicas como brillantes, logrará el poder, dejando a su paso un camino sembrado de muertes violentas. En palabras de la propia Resino, «rechaza el papel que la sociedad y la preeminencia masculina le han asignado, luchará por contestar estos esquemas y conseguir el poder» (3). De este modo, Wu-Tso se revela como un personaje femenino que se rige por un código impensable en su época y que expresa su intención de lograr sus propósitos a toda costa: «Yo quiero ser siempre yo, resultar nueva cada mañana y llevarme a la boca cada día un bocado distinto» (56).

Irónicamente, la princesa acaba también por convertirse en una víctima de sus propias aspiraciones. Wu-Tso debe renunciar al amor, ilícito, que encuentra en el general Taisho, y sus acciones traen como resultado su propia muerte, como ha sucedido con sus antecesores. La misma protagonista del drama esboza una triste mueca en su último aliento, con lo que reconoce su derrota, y con eso lo que se refleja en la obra es el hecho de que Wu-Tso sólo va a ser reconocida como emperador una vez que ha muerto.

En el drama de Resino son visibles los elementos clásicos del cuento, si bien han sido transformados y adaptados. Aunque ha nacido princesa, Wu-Tso no vive en un castillo esperando a su príncipe, sino que está obligada a un matrimonio político: «Por muy bien que la naturaleza te haya dotado, tu destino es otro. [...] Dar hijos al emperador de Japón» (27). Por otra parte, el objeto mágico del cuento no es otro que el poder, y el dragón a vencer es el patriarcado, que le recuerda constantemente la inaccesibilidad al poder por su condición de mujer.

Como vemos, enemigo formidable, y presente en numerosos cuentos de hadas, el dragón se erige como el gran obstáculo para el final feliz. Desatado y desbocado, la fuerza del dragón puede llegar a ser destructiva, pero promete algo mejor y más hermoso si se logra vencerlo: el beso de amor verdadero, la transformación de la sirvienta en reina o el joven humilde que se convierte en rey. Y, sin embargo, en el cuento tradicional, su destrucción rara vez ocurre a 
manos de una mujer. Así pues, debemos resaltar que, al enfrentarse al dragón del patriarcado, Wu-Tso desafía el papel tradicional de princesa cautiva e indefensa, y toma el lugar del héroe que se enfrenta al desafío último.

En este sentido, precisamente es un rasgo característico tanto del cuento de hadas feminista como de la dramaturgia femenina de los 80 el que el elemento de subversión más evidente se encarne en la protagonista femenina. Wu-Tso dista de ser una mujer pasiva que espera la llegada de un príncipe que la libere de sus ataduras. Resino la describe como: «Bella y delicada. Es absolutamente indispensable para la adecuación del personaje su apariencia frágil, lo que contrastará con su enorme fuerza interior e incluso su destreza física» (9). Además, en su primera aparición, Wu-Tso aparece «ataviada como un guerrero de modo que cuesta identificarla con una mujer» (25). Al igual que en los cuentos tradicionales, se hace hincapié en la belleza de la princesa, pero ya en la descripción inicial que Resino hace de su personaje, aparecen los síntomas de transgresión cuando afirma que «es una mujer joven y bella, con brevedad y armonía de muñeca. Sus facciones, no obstante y a pesar de su delicadeza, dejarán escapar algo terrible y cuando no se sienta observada, su belleza se descascarillará» (9). Ese resquicio en su belleza desvela la verdadera personalidad de la princesa: una mujer determinada, dispuesta a romper las leyes y a manipular a los que la rodean en su propio beneficio y a cualquier precio. De este modo, WuTso observa «con evidente desprecio» a Fu-Hi, quien va a convertirse en su esposo, y declara que «si no es capaz de aguantar mi mirada mal podrá sostener la espada» (35). Asimismo, aun casada con $\mathrm{Fu}-\mathrm{Hi}$, Wu-Tso comienza un romance ilícito con el general Taisho. El inicio de la seducción entre ambos se representa de forma paralela al suicidio de $\mathrm{Fu}-\mathrm{Hi}$, quien decide auto inmolarse en un intento de lograr una reparación de la situación en la que todos los personajes se hallan inmersos. La escena es descrita como «un bordado de encuentros y persecuciones: un tiovivo exacerbado y sensual» (45), al tiempo que Fu-Hi «desenvaina despacio la espada [...] y la alzará sobre su vientre. [...] Finalmente se la clavará lanzando un agudo grito» (46). Por lo tanto, la fantasía amorosa del cuento tradicional es sustituida por un erotismo crudo y agresivo, subvirtiendo efectivamente el estereotipo femenino romántico y sumiso.

La culminación de la relación entre Wu-Tso y Taisho viene a funcionar como el principal punto de inflexión del drama. Tras haber eliminado a todos los que se interponen en su camino al trono:

Wu-Tso y el general están inmersos en su amor. [...] Después, Wu-Tso se incorpora penosamente. Taisho sigue en el suelo de espaldas al espectador. Wu-Tso le mira jadeante y con el pie, le da la vuelta: Taisho está muerto, con 
su espada clavada en el vientre. Wu-Tso sonríe de forma siniestra: de su boca brota un hilillo de sangre. Trabajosamente, cogerá la espada del Emperador y su kammuri e irá subiendo hacia el trono. Una vez allí [...] colocará la espada sobre sus rodillas Y sobre su cabeza el kammuri. Seguidamente, abre su kimono y en su total desnudez habrá una enorme herida. [...]Wu-Tso intentará reír abiertamente pero será una risa inaudible: simplemente una mueca nacida del propio cadáver que ya convive con ella. (64)

Este momento de la obra teatral supone la subversión última del cuento, ya que la unión amorosa de $\mathrm{Wu}$-Tso y Taisho se descubre como un ritual en el que se entremezclan amor y muerte, y, por ende, como un macabro contraste al beso de amor verdadero que encamina el cuento de hadas al preceptivo final en el que «vivieron felices para siempre».

Por otro lado, merece la pena examinar asimismo el resto de las figuras femeninas de la pieza. En primer lugar, la madre de $\mathrm{Wu}$-Tso vive dominada por el sistema patriarcal y existe como una representación de «las mujeres de la época en particular, pero también el símbolo de las mujeres a través de la historia» (9). Su discurso es únicamente el del sufrimiento. Ante los deseos de poder de $\mathrm{Wu}$-Tso y su negativa a la resignación, replica: «Te quedan dos caminos, Wu-Tso: la resignación o la desgracia. Si te resignas todo llegará a serte indiferente, con lo cual el sufrimiento puede parecerte otra forma de ventura» (29). Sus palabras se revelan como un presagio del final de su hija, y personifica la falta de opciones para la mujer. Por otra parte, la emperatriz de Japón encarna otra interpretación del mismo concepto. Acostumbrada a su papel secundario, «el trono y la dignidad imperial es lo primero para ella y al afianzamiento de su dinastía dedicará sus últimas fuerzas» (10). Es así que reconoce a $\mathrm{Wu}$-Tso como una amenaza y se une al patriarcado para subyugarla.

Igualmente, debemos prestar atención a los referentes masculinos del drama. El padre de Wu-Tso es descrito como «el poder omnímodo y patriarcal de una época de preeminencia masculina en la que éste decidía los últimos movimientos de sus hijos y, sobre todo, de sus hijas» (14). Por su parte, el personaje del General Taisho merece mención especial. Descrito a través de su valor y de las proezas que ha llevado a cabo, al final no es capaz de cumplir con su papel de héroe salvador. Como reseña Resino: «ha hecho de la fidelidad al trono y a las armas su única razón», y aunque «siente que es frágil» (12) ante la seducción de la princesa, al final también se consolida como parte del patriarcado que intenta reprimir a $\mathrm{Wu}$-Tso.

Por tanto, como estamos viendo, la verdadera maldición de la princesa reside en la imposibilidad de escapar de su condición de mujer, o lo que es lo mismo, en su incapacidad para vencer al dragón del patriarcado. Al final de la obra, el señor de Kamakura llega hasta el trono donde se encuentra el cadáver 
de $\mathrm{Wu}$-Tso, tras haberse hecho con el palacio imperial, y después de contemplar la figura del emperador Wu-Tso, ya sin vida, el señor de Kamakura la toma en sus brazos y la presenta a sus soldados como «la más bella de las ofrendas. Ninguno podría pensar en un botín más significativo y hermoso» (65). Por consiguiente, $\mathrm{Wu}$-Tso ha sido derrotada incluso en su muerte, donde una vez más es despojada de su agencia y de su subjetividad para convertirse en un mero objeto, definido por su belleza.

En suma, Resino presenta un drama en el que los temas de agencia, voz y poder son centrales. Tradicionalmente, la posición de poder respaldada suele situarse con el protagonista masculino, pero Nueva Historia está tratando de iluminar otros discursos de género para la audiencia. El género está tan arraigado en nuestra cultura, nuestros comportamientos, nuestras actitudes y nuestros deseos que parece completamente innato. Sin embargo, el género en sí mismo es un fenómeno que se construye y difunde a través de prácticas sociales de maneras distintivas, en diferentes contextos y con una variedad de personas. Históricamente, el género ha sido visto como claramente definido y binario: dos categorías distintas, masculina y femenina. Butler argumentó «act which is both intentional and perfomative» (139), pero existen restricciones sociales sobre quién debe actuar. Como hemos visto en Nueva historia, si estas limitaciones sociales no se cumplen, puede haber consecuencias para comportamientos que se consideran socialmente inapropiados.

Sin embargo, Nueva historia toma una posición de rechazo a los estereotipos de género, su personaje principal lucha por su voz y su agencia, y expresa su rechazo al discurso masculino dominante tradicional para iniciar una estructura de poder de género alternativa. El papel arquetípico de las mujeres en las versiones tradicionales de la historia -como la víctima vulnerable, damisela en apuros o el premio bonito para el héroe masculino- ha sido expuesto, reescrito y, en última instancia, recuperado para las mujeres. Los elementos del cuento de hadas no sólo proporcionan a Resino un material radical y represivo, sino que también le permiten rechazar la voz autorizada a favor de la voz femenina que ha sido reprimida. La princesa Wu-Tso no es una restauración feminista sencilla o idealizada, sino que ha sido creada partir de una humanidad intrincada que le permite trascender los roles de género convencionales.

Nueva historia funciona como cuento de hadas feminista en tanto que Resino ofrece una promesa de nueva percepción de género, logra alterar las visiones de la audiencia en términos de imágenes tradicionales de género, sus pautas y sus códigos, y ofrece una versión dramática en la que la historia ha sido modificada en aspectos esenciales. A través de una heroína implacable y determinada, Resino derriba asunciones respecto a los roles de género al tiempo 
que muestra que las construcciones de género siguen estando presentes. Como Crew argumenta, las reescrituras de los cuentos «challenge and make visible sexist discourses» (92), de forma que la audiencia, conocedora del género, podrá identificar formas alternativas de actuar de una manera socialmente más justa. Las verdades universales de los cuentos tradicionales ya no son dominantes, y las creencias sociales inscritas en ellos han sido alteradas y, sobre todo, cuestionadas.

Sin embargo, debemos matizar algunos aspectos acerca de esta dramaturgia, ya que las subversiones encontradas en estos textos no funcionan de manera absoluta como voces liberadoras de una sociedad represiva. Mientras estos dramas pueden entenderse como una reclamación de apertura de costumbres y cambio de valores, también son un reflejo de sentimientos de dolor, soledad e incomunicación. No obstante, es en esta opresión donde se encuentra una de las claves del teatro de Resino y del resto de las autoras teatrales de los 80 . Al presentar una serie de personajes femeninos oprimidos y las diferentes resoluciones de sus historias alejadas del preceptivo matrimonio como final feliz, o al menos de un final feliz convencional, se pone de manifiesto la dicotomía entre la mujer representada tradicionalmente y la mujer real. Nuestras autoras muestran cómo los diferentes valores y las relaciones del poder no deben darse por sentados. Es así que sus dramas se convierten en una crítica al sistema y expresan la necesidad de romper esa dicotomía opresiva de sumisión. Sus dramas apelan a la necesidad de hacer desaparecer la limitación de la mujer y también de potenciar valores femeninos positivos. Los conflictos que se manifiestan en Nueva historia de la princesa y el dragón se revelan como atemporales, haciendo hincapié en los obstáculos que encuentra la mujer, de antes y de ahora, sea princesa o plebeya.

Asimismo, el material que aportan estas dramaturgas a través de su producción es enormemente enriquecedor para debatir la situación y reflexiones de la mujer en la España del momento. Las ambigüedades y las diferencias deben ser analizadas como un reflejo de los acontecimientos dramáticos y cambios vertiginosos que España experimentó durante el siglo XX, especialmente desde el punto de vista de la mujer en una época en la que existe un choque y también una convivencia, desde el conflicto entre la libertad que trajo la democracia y el concepto esencialista de la mujer que había sido característico de España durante mucho tiempo, y que aún persiste en los momentos en que aparece esta producción teatral. De este modo, es posible afirmar que, aunque no se puede hablar de una aplicación del discurso feminista de una forma radical, bien podemos señalar la existencia de una estética femenina en las estrategias de 
representación en tanto que nos ofrecen personajes que son únicos, diferentes y muestran una clara consciencia de sí mismos, sus pensamientos y emociones.

Existen muy pocos finales felices en esta producción teatral. Las protagonistas de las piezas luchan contra los preceptos aprendidos en la época, sufriendo enormemente por ello en numerosas ocasiones. No obstante, las representaciones de estas mujeres amplían los límites de lo que significa ser «subversiva» o «transgresora». Así, poco a poco, lo que antes resultaba impensable ahora se representa o al menos se publica, y temas que eran considerados tabú van surgiendo en estas obras. Al mismo tiempo, estas autoras permiten que sus personajes cuestionen ciertos conceptos que antes se daban por sentados, como el silencio de la mujer durante la dictadura, la censura, auto impuesta en innumerables casos, o la abnegación y pasividad tradicionalmente inherentes a la condición femenina. En este sentido podemos afirmar que existe un claro elemento de rebelión contra el legado social, teatral y cultural de la dictadura que persiste a pesar de la instauración de la democracia.

\section{CONCLUSIONES}

El análisis de esta obra nos lleva a reconsiderar las características de las mujeres que han poblado la escena en el teatro español a través de un contraste entre los modelos antiguos y su convivencia con estas nuevas representaciones que luchan por desterrarlos, en una encrucijada ideológica en la que se producen grandes cambios en los estándares sociales y donde se hace imprescindible definir la identidad, encontrar una voz y despertar la conciencia, lo que afecta no solo a sus obras sino, también, al resto de la sociedad española.

Aunque la crisis del teatro español afectó irremisiblemente a nuestras autoras, y muchas de ellas han abandonado la producción dramática, es indudable que sus obras despertaron una conciencia dormida en una audiencia que asistió a una nueva producción teatral que logró crear nuevas formas de mirar y reflejó las nuevas expectativas y preocupaciones de la mujer en un momento de cambio político y social.

En conclusión, Nueva historia de la princesa y el dragón y la producción dramática de las dramaturgas de los 80 actuaron como vehículos de apertura que han contribuido a la legitimización de los sujetos femeninos que se muestran en los márgenes del sistema. Aunque sencillas en apariencia, estas piezas se atreven a cuestionar la estabilidad de la sociedad, de la sexualidad y, en definitiva, de los valores sociales, culturales y morales arraigados en la ideología hegemónica de la España de la época. Y no menos importante, se constituyen en una celebración de lo diferente y descubren una diversidad de voces que tradicionalmente han sido silenciadas. 


\section{REFERENCIAS BIBLIOGRÁFICAS}

Askyz, Urszula, «Las mujeres dramaturgas en España: en busca de la identidad». Estudios sobre escritoras hispánicas en honor de Georgina Sabat-Rivers. Ed. Lou Charnon-Deutsch. Madrid: Editorial Castalia, 1992, 45-61.

Butler, Judith. Gender trouble. New York, NY: Routledge, 1990.

Crew, Hilary S. «Spinning new tales from traditional texts: Donna Jo Napoli and the rewriting of fairy tale». Children's Literature in Education 33.2 (2002): 77-95.

Gabriele, John P. «Estrategias feministas en el teatro breve de Carmen Resino». Letras Femeninas 1/2 (1995): 85-95.

García-Pascual, Raquel (ed.). Dramaturgas españolas en la escena actual. Madrid: Castalia, 2011.

Gilbert, P. (1994). «And they lived happily ever after: Cultural storylines and the construction of gender». The need for story: Cultural diversity in classroom and community. Eds. Dyson A. H. y C. Genishi. New York, NY: Teachers CollegePress, 124-145.

Haase, Donald. Fairy Tales and Feminism: New Approaches. Detroit: Wayne State University Press, 2004.

Lázaro, Maribel. «Los horizontes del teatro español. Nuevas autoras». Primer Acto 220 (1987): 10-21.

O'Connor, Patricia. « ¿Por qué no estrenan las mujeres en España?». Estreno 10.2 (1984): 13-25.

O'Connor, Patricia. Dramaturgas españolas de hoy. Una introducción. Madrid: Fundamentos, 1988.

O'Connor, Patricia. «Women Playwrights in Contemporary Spain and the MaleDominated Canon». Signs 2 (1990): 376-390.

Paco, Mariano de. «El Teatro Histórico De Carmen Resino». Anales de la Literatura Española Contemporánea 3 (1995): 303-314.

Pedrero, Paloma. «Los horizontes del teatro español. Nuevas autoras». Primer Acto 220 (1987): 10-21.

Resino, Carmen. El Presidente. Madrid: Quevedo, 1968.

Resino, Carmen. Nueva historia de la princesa y el dragón. Madrid: Lucerna, 1989.

Rowe, Karen E. «Feminism and Fairy Tales.» Women's Studies 6.3 (1979): 209-226.

Salinero Cascante, Maria Jesús. «El cuerpo femenino y su representación en la ficción literaria». Piel que habla. Eds. M. Azpeitia, M. J. Barral, L. E. Díaz, T. González Cortés, E. Moreno, T. Yago. Barcelona: Icaria, 2001, 39-76.

Serrano, Virtudes. «Hacia una dramaturgia femenina.» Anales de la Literatura Española Contemporánea 3 (1994): 343-364.

Velázquez, José Luis y Javier Memba. La generación de la democracia: historia de un desencanto. Madrid: Ediciones Temas de Hoy, 1995.

Zipes, Jack David. Fairy Tales and the Art of Subversion: The Classical Genre for Children and the Process of Civilization. New York: Wildman Press, 1983. 